\title{
Biodegradation of a Complex Phenolic Industrial Stream by Bacterial Strains Isolated from Industrial Wastewaters
}

\author{
Alejandra Bartolomé ${ }^{1}$, Gema Rodríguez-Moro ${ }^{2,3}{ }^{\mathbb{D}}$, Juan-Luis Fuentes ${ }^{1}$ (D), Mariana Lopes ${ }^{4}$, Juana Frontela ${ }^{4}$, \\ Jesús Lázaro ${ }^{4}$, María Cuaresma 1,3 ${ }^{1}$, José-Luis Gómez-Ariza 2,3, Tamara García-Barrera ${ }^{2,3}$ \\ and Carlos Vílchez $1,3, *$ (D)
}

Citation: Bartolomé, A.; Rodríguez-Moro, G.; Fuentes, J.-L.; Lopes, M.; Frontela, J.; Lázaro, J.; Cuaresma, M.; Gómez-Ariza, J.-L.; García-Barrera, T.; Vílchez, C. Biodegradation of a Complex Phenolic Industrial Stream by Bacterial Strains Isolated from Industrial Wastewaters. Processes 2021, 9, 1964. https://doi.org/ $10.3390 /$ pr9111964

Academic Editor: Davide Dionis

Received: 18 September 2021

Accepted: 26 October 2021

Published: 3 November 2021

Publisher's Note: MDPI stays neutra with regard to jurisdictional claims in published maps and institutional affiliations.

Copyright: (c) 2021 by the authors. Licensee MDPI, Basel, Switzerland. This article is an open access article distributed under the terms and conditions of the Creative Commons Attribution (CC BY) license (https:/ / creativecommons.org/licenses/by/ $4.0 /)$.
1 Algal Biotechnology Group, CIDERTA and Faculty of Experimental Sciences, University of Huelva, Huelva Business Park, 21007 Huelva, Spain; ale18186@gmail.com (A.B.); jlfuentes@dqcm.uhu.es (J.-L.F.); maria.cuaresma@dqcm.uhu.es (M.C.)

2 Environmental and Bioanalytical Chemistry Group, Department of Chemistry “Professor José Carlos Vílchez Martín", Faculty of Experimental Sciences, University of Huelva, Campus El Carmen, 21007 Huelva, Spain; gema.moro@dqcm.uhu.es (G.R.-M.); ariza@uhu.es (J.-L.G.-A.); tamara@uhu.es (T.G.-B.)

3 Research Center of Natural Resources, Health and the Environment (RENSMA), University of Huelva, 21007 Huelva, Spain

4 Cepsa's Research Center, 28805 Alcalá de Henares, Madrid, Spain; mlopes@cepsa.com (M.L.); juana.frontela@cepsa.com (J.F.); jesusjavier.lazaro@cepsa.com (J.L.)

* Correspondence: cvilchez@uhu.es; Tel.: +34-959218442; Fax: +34-959219942

\begin{abstract}
Molecular and metabolomic tools were used to design and understand the biodegradation of phenolic compounds in real industrial streams. Bacterial species were isolated from an industrial wastewater treatment plant of a phenol production factory and identified using molecular techniques. Next, the biodegradation potential of the most promising strains was analyzed in the presence of a phenolic industrial by-product containing phenol, alfa-methylstyrene, acetophenone, 2-cumylphenol, and 4-cumylphenol. A bacterial consortium comprising Pseudomonas and Alcaligenes species was assessed for its ability to degrade phenolic compounds from the phenolic industrial stream (PS). The consortium adapted itself to the increasing levels of phenolic compounds, roughly up to $1750 \mathrm{ppm}$ of PS; thus, becoming resistant to them. In addition, the consortium exhibited the ability to grow in the presence of PS in repeated batch mode processes. Results from untargeted metabolomic analysis of the culture medium in the presence of PS suggested that bacteria transformed the toxic phenolic compounds into less harmful molecules as a survival mechanism. Overall, the study demonstrates the usefulness of massive sequencing and metabolomic tools in constructing bacterial consortia that can efficiently biodegrade complex PS. Furthermore, it improves our understanding of their biodegradation capabilities.
\end{abstract}

Keywords: phenolic compounds; biodegradation; Pseudomonas; Alcaligenes; massive sequencing; metabolomics

\section{Introduction}

Phenolic compounds constitute a group of pollutants that are difficult to remove from the streams or by-products that contain them. The major industries associated with the production of phenol-containing streams or by-products are petrochemicals, petroleum oil refineries, coal mining, and coke oven plant [1-3]. Phenolic pollutants are undergone to active transformations inside living organisms and generate more toxic electrophilic metabolites in a reaction mediated by the cytochrome P450 enzyme system. These active metabolites may bind to and damage DNA or other vital enzyme systems of living organisms [4,5]. Thus, there is an urgent need to design tools for efficiently removing phenolic compounds from industrial streams and industries to implement environmentally friendly technologies. These steps can eventually lead to economic benefits derived from, e.g., the use of by-products resulting from the remediation process. 
Bioremediation is considered one of the most attractive environmentally friendly tools to deal with carbon-based chemicals and pollutants that can severely impact the living systems. The ability of numerous microorganisms to degrade phenol and phenol-related compounds has been extensively studied. In this sense, phenol is not just a carbon source for bacteria but it has also been shown to act as bacterial growth promoter [6]. Bacterial species of several genera, including Pseudomonas, Sphingomonas, Ralstonia, Cupriavidus, Burkholderia, Acinetobacter, Rhodococcus, and Arthrobacter, are usually found in sites contaminated by phenolic compounds. As an example of the latter, high density formation of non-fermenting bacteria as well as coliforms were observed in cultures of the aquatic plant Lemna minor exposed to different levels of bisphenol A while colonies of the plant ceased to grow, as a sign of the bacterial capabilities to make efficient catabolic use of phenolic derivates [7]. Several research groups have reported the biodegradation kinetics of phenol and derivates by these species along with the genes encoding for the metabolic pathways partly or completely [8,9]. The use of selected bacterial strains to treat sites contaminated by phenolic compounds is gaining importance as a promising bioremediation tool that could replace other less environmentally friendly methods $[9,10]$. Massive sequencing boosts the accurate selection of specific strains with outstanding biodegradation capabilities, thereby developing successful bioremediation solutions to complex pollution problems.

The majority of studies have analyzed the potential of bacterial species to degrade only a specific compound [11,12]. However, an industrial stream is frequently contaminated with multiple pollutants that should be removed to improve the effluent quality. In addition, the chemical and physical characteristics of the industrial stream ( $\mathrm{pH}$, viscosity, solubility in water, and chemical composition) greatly differ from those of any artificial culture medium prepared in the laboratory using standard nutritional media containing a specific organic molecule. Consequently, the results from biodegradation tests in such a scenario could not necessarily be representative of a real situation where a bacterial consortium is used against several phenolic compounds in a complex stream. In addition, the presence of several phenolic compounds might result in the enhanced biodegradation of other compounds due to its increased bioavailability chemically induced by the others. For instance, phenol, an amphiphilic compound containing both a hydrophobic phenyl ring group and a hydrophilic phenolic hydroxyl group, could significantly enhance the bioavailability of polycyclic aromatic hydrocarbons (PAHs) [13]. Consequently, studies on the biodegradation of phenolic compound-containing complex streams can provide biological solutions to remove them from real matrices. Furthermore, it may provide an insight into the chemical evolution occurring in such a complex media through microbial action.

The low solubility of phenolic compounds in water reduces their availability to bacterial cells in aqueous cultures and therefore limit biodegradation yields. This limitation can be overcome, for instance, by maximizing the contact surface between bacteria and phenolic compounds. This can be achieved by (i) vigorous mechanical mixing of a non-miscible mixture of bacterial culture (in water) and the added aliquot of the industrial stream and (ii) adding surfactants and amphiphilic compounds that can reduce the interfacial free energy, altering the surface area at low concentrations [14]. The increased contact between the aqueous phase containing bacterial species and the organic phase from the industrial stream enhances the chances of efficient biodegradation. In this study, emulsions formed by aliquots of the phenolic stream and bacterial suspensions were used to maximize the contact between cells and compounds to be eventually degraded. Metabolomics provides powerful analytical tools, enabling researchers to determine the media composition and further understand the chemical and biochemical transformations.

This work is an attempt to study the biodegradation features of complex, real phenolic streams using molecular and metabolomic tools and suitable bacterial species with biodegradation capacities. We have also simultaneously described certain chemical changes occurring in cultures. 


\section{Materials and Methods}

\subsection{Phenolic Industrial Stream}

An industrial stream rich in phenolic compounds was selected as raw material to assess the biodegradation potential of selected bacterial species. The phenolic industrial stream (PS) was kindly provided by CEPSA (Compañía Española de Petróleos, S.A.U.), Spanish Petroleum Company. PS is a by-product stream of phenol production which is difficult to handle and treat. The chemical composition of PS is summarized in Table 1, together with the chemical names and concentrations of all components.

Table 1. Chemical composition of PS used for biodegradation experiments. Concentration data are expressed in percentage $(\%, w / v)$ of each component in the PS. ACP: acetophenone; PMDC: 2-phenyl-2-propanol; 2CP: o-cumylphenol; DimAMS1: 1,1'-(1,3,3-trimethylprop-1-ene-1,3-diyl)dibenzene; PCP: 4-cumylphenol and BPA: BisphenolA.

$\begin{array}{cccc}\text { Phenol } & \text { PCP + Heavies } \\ \begin{array}{c}\text { Soncentration }(\%, w / v) \\ \text { Solubility in water } \\ \left(\mathrm{g} / \mathrm{L}, 20{ }^{\circ} \mathrm{C}\right)\end{array} & 5.5 & \text { PMDC }\end{array}$

* PCP + heavies: maximum PCP concentration in the PS is usually about $30-35 \%$. The remaining percentage until $50 \%$ corresponds to non-identified intermediate and heavy compounds, so-called heavies.

PS was used as a source of phenolic compounds and was added at different concentrations $(w / v)$ to the bacterial cultures during biodegradation assays, as detailed in the Results and Discussion section.

\subsection{Massive Sequencing, Isolation, Growth, and Identification of Bacterial Strains}

The bacterial strains used in this work were isolated from the aqueous effluent treatment plant (ETP) of CEPSA-Química, a phenol-producing company located in Palos de la Frontera, Huelva (Spain). The ETP treats aqueous effluents contain low levels of phenol and phenolic structure-related compounds and are based on secondary biological treatment for organic matter oxidation. Accordingly, as a strategy of this work, liquid samples from the ETP's biological treatment pond were used as bacterial source with the potential to degrade phenolic compounds. The liquid samples were taken directly from the ETP's high oxidation rate pond, in $1 \mathrm{~L}$ glass bottles that were kept cold, at $4{ }^{\circ} \mathrm{C}$, and in darkness until use. The samples were processed in the laboratory within a maximum time frame of $3 \mathrm{~h}$ after collected from the ETP.

On one hand, the microbial diversity present in the ETP's liquid samples was first identified by massive sequencing of the total DNA extracted from the ETP's samples. The aim was to obtain the microbial composition of the community present in the ETP. The samples taken from the ETP had $1 \mathrm{~L}$ volume. The procedure started by harvesting $1 \mathrm{~mL}$ ETP's samples by centrifugation at 14,000 rpm for $3 \mathrm{~min}$. Subsequently, the total DNA of the cell pellets was extracted using the i-Genomic Soil commercial extraction kit (iNtRON Biotechnology, Luzern, Switzerland). The bacterial 16S rRNA gene was amplified by PCR with the universal primers 533R (reverse) and 492F (forward). The reaction volume per PCR tube was $20 \mu \mathrm{L}$ and contained the following components: $10 \mu \mathrm{L}$ Taq DNA Polymerase; the universal primers, $1 \mu \mathrm{L}$ each of $10 \mu \mathrm{M}$ concentrations; $0.5 \mu \mathrm{L}$ total DNA; molecular grade water, $7.5 \mu \mathrm{L}$. In total, 4 replicates were performed in order to obtain enough final product, according to sequencing company requirements. The cycling conditions used were: $94{ }^{\circ} \mathrm{C}$ for $30 \mathrm{~s}$, followed by 30 cycles of $94{ }^{\circ} \mathrm{C}$ for $35 \mathrm{~s}, 58^{\circ} \mathrm{C}$ for $35 \mathrm{~s}$ and $72{ }^{\circ} \mathrm{C}$ for $1 \mathrm{~min}$. The PCR product was directly purified using the E.Z.N.A. Cycle Pure Kit from OMEGA Bio-Tek (Norcross, GA, USA), followed by massive sequencing performed by 
Secugen S.L. (Madrid, Spain), which compared the obtained sequences with those available in the Ribosomal Database Project from Michigan State University.

On the other hand, sample aliquots from the ETP were cultured in liquid standard culture medium (LB and TSB, described below) to promote growth of the present bacteria. After 3-4 days of growth, aliquots from these cultures were taken to inoculate fresh culture medium, at an OD of 0.5, supplemented in PS concentrations up to $70 \mathrm{ppm}$ PS. The aim was promoting growth of bacterial species with tolerance to PS. After 3-4 days of growth, aliquots $(100 \mu \mathrm{L})$ from these PS-added liquid cultures were plated on Petri dishes containing different culture media, prepared in agar at $1.75 \%(w / v)$ for bacterial growth, aimed at isolating the bacterial species that survived in the presence of PS. Three different culture media were prepared: LB, TSB, and CECT. These three media were used to recover as many species as possible of the bacterial biodiversity present in the ETP samples. The LB medium contains (per $1 \mathrm{~L}$ ) $10 \mathrm{~g}$ of $\mathrm{NaCl}, 5 \mathrm{~g}$ of tryptone, and $5 \mathrm{~g}$ of yeast extract. TSB contains (per $1 \mathrm{~L}$ ) $5 \mathrm{~g}$ of NaCl, $17 \mathrm{~g}$ of tryptone, $2.5 \mathrm{~g}$ of glucose, and $2.5 \mathrm{~g}$ of $\mathrm{K}_{2} \mathrm{HPO}_{4}$. The CECT medium contains (per $1 \mathrm{~L}$ ) $0.19 \mathrm{~g}$ of $\mathrm{CaCl}_{2}, 2 \mathrm{~g}$ of yeast extract, $5 \mathrm{~g}$ of glucose, $0.2 \mathrm{~g}$ of $\left(\mathrm{NH}_{4}\right)_{2} \mathrm{SO}_{4}, 3 \mathrm{~g}$ of $\mathrm{KH}_{2} \mathrm{PO}_{4}$, and $0.5 \mathrm{~g}$ of $\mathrm{MgSO}_{4} \cdot 7 \mathrm{H}_{2} \mathrm{O}$. The plates were incubated at $30{ }^{\circ} \mathrm{C}$ for about $48 \mathrm{~h}$. The bacterial colonies with visible appearance in the plates were replicated in new plates and incubated at $30^{\circ} \mathrm{C}$ for about $48 \mathrm{~h}$ to produce and isolate clones of specific bacterial strains for further identification. Individual clones of different characteristics were regrown in their corresponding liquid culture media (LB, TSB, or CECT) at $30{ }^{\circ} \mathrm{C}$ to obtain sufficient biomass for identification purposes. After $48 \mathrm{~h}$ of growth, $1 \mathrm{~mL}$ of samples from these cultures of different bacterial species were harvested, and the bacterial pellets were used for DNA extraction. The DNA was extracted using the i-Genomic Soil commercial extraction kit (iNtRON Biotechnology, Luzern, Switzerland). The quality of extracted DNA was assessed by electrophoresis using 1\% agarose gel (loading $6 \mu \mathrm{L}$ per well, composed of $3 \mu \mathrm{L}$ DNA-sample and $3 \mathrm{~mL}$ load buffer) for a single intact band. The single DNA bands obtained were purified using the E.Z.N.A. Cycle Pure Kit from OMEGA Bio-Tek (Norcross, GA, USA) and further sequenced by Secugen S.L. (Madrid, Spain). The specific sequences obtained from the sequencing company were analyzed in our laboratory to identify each bacterial strain. The sequences were edited and assembled by using ChromasPro 1.5 software and first analyzed through CLC Main Workbench (version 6.7.1). The sequences were subsequently analyzed using BlastN software against the non-redundant database available in GenBank (www.ncbi.nlm.nih.gov/blast/Blast/cgi; accessed on 28 May 2020).

In addition, the standard culture media referred above (LB, TSB, CECT) were also used, where indicated in this manuscript, for bacterial growth long-term experiments in liquid cultures, either with or without added PS. Where indicated, the LB culture medium was prepared in clean, treated water from CEPSA's ETP (TW), instead of in deionized water. Specific cultivation conditions of each experiment are given in the Results and Discussion section.

\subsection{Bacterial Growth in Standard and PS-Supplemented Culture Media}

The identified bacterial species were tested for their natural biodegrading capabilities in the presence of PS aliquots added to bacterial cultures. The bacterial species were first grown in the standard culture medium to determine their maximum growth rates, which were used as a reference for the maximum growth capacity of tested strains. The standard bacterial cultures were grown in an incubator at $30^{\circ} \mathrm{C}$ in the dark and used as seed cultures to inoculate cultures used to test biodegradation activities. The most promising bacterial species for biodegrading PS compounds were cultivated together. The most suitable culture medium for growth among those described in Section 2.2 was selected based on the best growth performance of the bacterial consortium (Results and Discussion section). The biodegradation experiments were performed by adding PS aliquots $(w / v)$ to a culture medium without bacteria; the mix was vigorously homogenized using ULTRA-TURRAX until a completely homogeneous emulsion was formed. Subsequently, the PS-added culture 
medium was inoculated with a given bacterial strain or with the bacterial consortium prepared as described in the Results and Discussion section. For growth experiments, the culture medium used was inoculated from standard cultures at roughly 0.5 units of absorbance at $600 \mathrm{~nm}$ (Optical Density, OD), compared with the corresponding blank. In addition to using standard culture media, a close to real application culture medium was obtained by mixing clean, treated water from CEPSA's ETP and PS aliquots, and used in biodegradation experiments. The growth trends were followed spectrophotometrically, and the absorbance was recorded daily at $600 \mathrm{~nm}$.

For the repeated-batch cultivation experiment described in the Section 3.4, the culture media were prepared by vigorously mixing TW and PS aliquots. Three culture media were prepared, each of them with a different PS concentration (ppm): 700; 1048; and 1398. The media obtained had both appearance and consistency of an emulsion. The culture media were then inoculated at an initial OD of 0.5 , from bacterial standard cultures. Once inoculated, the cultures were allowed to grow until an OD value of 1.0-1.1 was reached, compared with the corresponding blank. This maximum OD value was selected based on experimental data of this work which showed growth to evolve at a constant rate at least below OD 1.0-1.1. Subsequently, the cultures were diluted each with its corresponding TW-PS stock emulsion, until the OD decreased to the initial value of roughly 0.5 . After each dilution step, the cultures were again allowed to grow until the OD 1.0-1.1. The growth-dilution process was repeated for a total of 4 cycles or until growth ceased. With this strategy, roughly half of the biomass and the remaining carbon sources (PS compounds) were removed from each medium in each dilution step. As explained, PS was re-supplied in each dilution step from each stock emulsion, and the remaining, active bacterial biomass grows on this supplied phenolic carbon.

\subsection{Extraction and Determination of Phenolic Compounds}

The conventional PS components present in culture media after the biodegradation process were determined using gas chromatography coupled to ion trap mass spectrometry (GC-IT-MS). The direct injection into the GC was not possible due to the water content in the culture media (required to grow the consortium). Thus, an analytical extraction method based on liquid-liquid extraction was optimized (LLE) as follows: $2 \mathrm{~mL}$ of toluene was added to $50 \mathrm{~mL}$ of sample, and the resulting organic phase was analyzed by GC coupled to an ion trap mass spectrometer (GC-MS) after vigorous shaking for $10 \mathrm{~min}$.

GC-MS analysis was performed on a Trace GC ULTRA model gas chromatograph coupled to an ITQ900 ion trap mass spectrometer detector (Thermo Fisher Scientific, Waltham, MA, USA), using an HP- $1100 \mathrm{~m} \times 250 \mu \mathrm{m} \times 0.5 \mu \mathrm{m}$ column (Agilent, Santa Clara, CA, USA). The extracts $(1 \mu \mathrm{L})$ were injected in the split mode with a split flow of $170 \mathrm{~mL} / \mathrm{min}$. The injector temperature was kept at $325^{\circ} \mathrm{C}$, and helium was used as a carrier gas at a constant flow of $1.7 \mathrm{~mL} / \mathrm{min}$. The temperature was set to $40^{\circ} \mathrm{C}$ for $5 \mathrm{~min}$ and subsequently increased to $325^{\circ} \mathrm{C}$ at $5^{\circ} \mathrm{C} \mathrm{min}^{-1}$, which was held for $8 \mathrm{~min}$.

\subsection{Sample Preparation for Untargeted Metabolomic Analysis}

The study design consisted of a microbial consortium grown in clean water from the industrial ETP exposed to PS (1454 ppm). After seven days of exposure, the metabolic profiles of both supernatant and the pellet, previously separated by centrifugation at $4000 \mathrm{~g}$ for $20 \mathrm{~min}$, were obtained. Subsequently, $1 \mathrm{~mL}$ of supernatant was vortexed-mixed with $1 \mathrm{~mL}$ of methanol (MeOH) and $100 \mu \mathrm{L}$ of methyl tert-butyl ether (MTBE) as extracting solvents. The mixture was homogenized for $30 \mathrm{~min}$ by vortexing and subsequently centrifuged at $4000 \mathrm{~g}$ for $10 \mathrm{~min}$ at $4{ }^{\circ} \mathrm{C}$ [15]. An aliquot of the obtained supernatant $(50 \mu \mathrm{L})$ was separated by GC-MS for analysis, and the remaining volume was used for UPLC-QTOF-MS. To obtain the cell fraction, the pellet was treated with $500 \mu \mathrm{L}$ of MeOH and $100 \mu \mathrm{L}$ of MTBE and homogenized with a glass-Teflon homogenizer to break the cell membrane. The mixture was centrifuged under conditions described above; $50 \mu \mathrm{L}$ of the supernatant was separated 
for GC-MS analysis, transferring the remaining volume to a vial for UPLC-QTOF-MS metabolomic analysis.

The GC-MS analysis involved a derivatization step that was performed following a previously described method [16] in two steps: (i) $50 \mu \mathrm{L}$ of the extract was dried under a stream of nitrogen and re-dissolved in $50 \mu \mathrm{L}$ of $20 \mathrm{mg} / \mathrm{mL}$ methoxyamine and (ii) after brief shaking; the samples were incubated at $80^{\circ} \mathrm{C}$ for $15 \mathrm{~min}$ in a water bath. Next, silylation was performed by adding $50 \mu \mathrm{L}$ of N-trimethylsilyl-N-methyl trifluoroacetamide (MSTFA) and incubated at $80^{\circ} \mathrm{C}$ for another $15 \mathrm{~min}$. Finally, samples were centrifuged at $4000 \mathrm{~g}$ for $1 \mathrm{~min}$, and the supernatant was transferred to a vial for analysis.

\subsection{Untargeted Metabolomics Analysis Using a Combined Analytical Multiplatform Based on GC-MS and UPLC-QTOF-MS}

\subsubsection{Metabolomic Analysis by GC-MS}

Metabolomic analysis by GC-MS was performed using a Trace GC ULTRA gas chromatograph coupled to an ITQ900 ion trap mass spectrometer detector (Thermo Fisher Scientific, Waltham, MA, USA). The column used was a Factor Four VF-5MS $30 \mathrm{~m} \times 0.25 \mathrm{~mm}$ ID, with $0.25 \mu \mathrm{m}$ film thickness (Varian). The extracts $(1 \mu \mathrm{L})$ were injected in the splitless mode. The injector temperature was kept at $280^{\circ} \mathrm{C}$, and helium was used as the carrier gas at a constant flow of $1 \mathrm{~mL} / \mathrm{min}$ [17]. Metabolites were separated with a temperature program from $100^{\circ} \mathrm{C}$ held for $0.5 \mathrm{~min}$ and subsequently increased to $320^{\circ} \mathrm{C}$ at $15^{\circ} \mathrm{C} / \mathrm{min}$, which was held for $7 \mathrm{~min}$. The acquisition was performed in full scan mode, with a mass range of $40-650 \mathrm{~m} / \mathrm{z}$. The data were processed with the XCMS software, included in the R platform, and later with the SIMCAPTM software for multivariate statistical analysis. The metabolites were identified using the NIST 08 mass spectral library (NIST, Gaithersburg, MD, USA), considering only variables with a probability greater than $80 \%$.

\subsubsection{Metabolomic Analysis by UPLC-QTOF-MS}

Next, metabolomic analysis using ultra-high-performance liquid chromatography coupled to quadrupole time of flight mass spectrometer (UHPLC-QTOF) was performed. The column used was a 6550 iFunnel Q-TOF LC/MS (Agilent, Santa Clara, CA, USA) as per a previously described method [18]. Briefly, $10 \mu \mathrm{L}$ of the extract obtained as described above was injected into a thermostated Agilent Poroshell EC-C18 column $\left(40^{\circ} \mathrm{C}, 100 \mathrm{~mm} \times 3 \mathrm{~mm}\right.$, $2.7 \mu \mathrm{m}$ ) (Agilent, Santa Clara, CA, USA). The mobile phase flow was $0.4 \mathrm{~mL} / \mathrm{min}$, with mobile phase A (10 mM ammonium formate in Milli-Q water) and mobile phase B (10 mM ammonium formate in acetonitrile). The conditions of chromatography were $75 \% \mathrm{~A}$ as the initial condition, decreasing to $5 \% \mathrm{~A}$ at $35 \mathrm{~min}$, and returning to the starting conditions in $36 \mathrm{~min}$, followed by $9 \mathrm{~min}$ of re-equilibration. Data were processed using Agilent technologies Profinder B.10.00 and Mass Profiler Professional software. Finally, the metabolites were identified by tandem mass spectrometry, and the resulting fragmentation spectra were matched with those in the METLIN database (La Jolla, CA, USA), considering only compounds with a probability greater than $80 \%$.

\subsection{Statistics}

Unless otherwise indicated, the data presented in this study are the means of three independent samples.

\section{Results and Discussion}

\subsection{Identification of Microorganisms with Potential for Degrading Phenolic Compounds}

Massive sequencing analysis was performed using samples from the liquid effluent treatment plant (ETP) of the industrial factory producing phenolic compounds (see the Materials and Methods Section). This analysis identified the bacterial species present in the ETP samples for their potential for biodegradation based on the available scientific information. The massive sequencing allowed us to determine the diversity and abundance 
of species present in the ETP samples, classified in terms of known bacterial families and genera. These are shown in Figure 1.
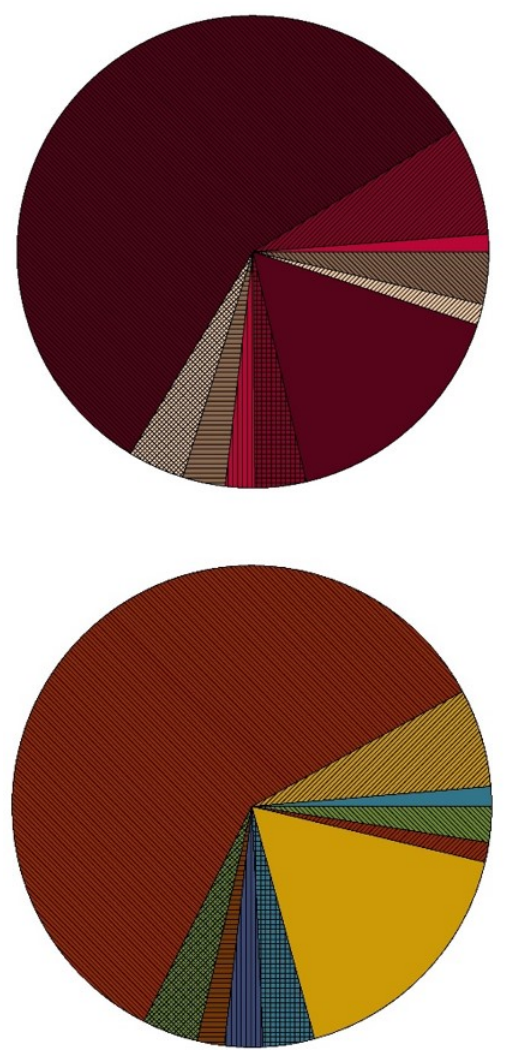
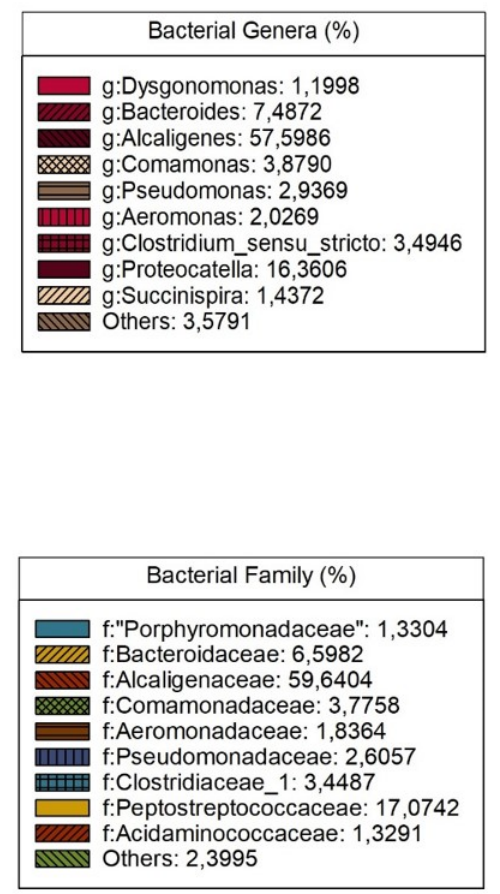

Figure 1. Taxonomic approach to the microbial families and genera found in samples from the ETP. Total DNA was extracted from the ETP's samples. Bacterial 16S rDNA was amplified and enough product was delivered to a sequencing company. The information obtained allowed us to describe the relative abundances of known microbial genera present in the samples. More details in the Materials and Methods section.

The results were analyzed in terms of the potential of bacterial species to degrade chemicals present in samples obtained from the ETP. This analysis was performed through a review of relevant literature (Table 2). The massive sequencing data showed the existence of several bacterial species that should theoretically be able to display the ability to degrade organic compounds, specifically phenolic compounds. Two of the species, namely P. putida and $A$. faecalis, were abundant in the bacterial mix present in the samples and displayed the genetic features to biodegrade phenol and phenolic compounds, according to previous works published by several authors (Table 2).

Pseudomonas putida possesses genetic features to degrade phenol at high concentrations, i.e., it can degrade more than $85 \%$ of phenol in cultures supplemented with $500 \mathrm{mg} / \mathrm{L}$ phenol [19] and even higher concentrations [20,21]. Cultures of Alcaligenes in the exponential phase showed the ability to degrade phenol similar to that displayed by P. putida in quantitative terms of phenol concentration biodegraded and the timing of the biodegradation kinetics [21]. Both these and several other bacterial species share key steps of the biochemical pathway for biodegradation of phenolic compounds. A critical step in the metabolism of aromatic compounds is the ring-cleavage step, which occurs via hydroxylation and fission of the benzene ring, mediated by dioxygenase-catalyzed reactions in aerobic bacterial cells. First, the ring is activated by the introduction of hydroxyl groups, and the subsequent ring fission is catalyzed by the cleaving enzyme catechol 1,2-dioxygenase or by catechol 2,3-dioxygenase, resulting in the following products: a cis-muconic acid for the former and 2-hydro cis-muconic semi aldehyde for the latter [22]. This catabolic pathway for phenol degradation results in the complete mineralization of the aromatic 
compound for aerobic species grown on phenol as the sole carbon source. Thus, several bacterial species derive energy by completely degrading high concentrations of phenolic compounds [21].

Table 2. Bacterial genera and biodegradation potential for organic compounds, including several bacterial genera detected by massive sequencing analysis in samples from the ETP.

\begin{tabular}{|c|c|c|}
\hline Microorganism Genus & Biodegradation Capability & Reference \\
\hline Desulfosporosinus & Toluene degradation & [23] \\
\hline Hyphomicrobium & Dicloromethane and dimethylsulfoxide degradation & [24] \\
\hline Flavobacterium & Phenol degradation & [25] \\
\hline \multirow{2}{*}{ Halomonas } & Phenol degradation & {$[26,27]$} \\
\hline & Nafthalene degradation & [27] \\
\hline Aeromonas & Potential for bioremediation of industrial effluents & [28] \\
\hline Pseudomonas & Aromatic compounds degradation & [11] \\
\hline Alcaligenes & Phenol and phenol derivates degradation & [29] \\
\hline \multirow{2}{*}{ Comamonas } & Tetrabromobisphenol degradation & [30] \\
\hline & 4-chlorophenol degradation & [31] \\
\hline
\end{tabular}

Despite the genetic ability to degrade chemical compounds, the presence of chemically diverse phenol derivates reduces the biodegradation effectiveness of the total organic carbon. This could be attributed to the fact that genetic biodegradation potentials of acting microorganisms differ, and the biodegradation process may generate different toxic intermediate products, especially depending on the original, complex composition of the organic compounds in wastewater. The chances of bacterial species to grow in a complex medium depend on their ability to adapt to other chemically synthesized organic compounds that are toxic to cells, and microorganisms may lack suitable genetic resources to completely degrade them [12].

Therefore, the next two steps in this work were (i) isolating, at least, the two species referred above, P. putida and $A$. faecalis, using suitable culture media and promoting their growth to construct a bacterial consortium, which will be used for producing sufficient biomass for biodegradation experiments; and (ii) adapting both bacterial species to the presence of PS.

\subsection{Construction of a Bacterial Consortium and Tolerance to the PS}

According to the bacterial variability found in the samples from the ETP and their availability of genetic resources to biodegrade organic compounds, several culture media were selected to promote the growth of the most abundant species. The literature analysis also confirmed the ability of these species to degrade phenolic compounds. The culture media selected were LB, TSB, and CECT. Overall, these media preserved the maximum number of species present in the ETP samples. LB and TSB are common media with organic carbon sources for bacterial growth. The use of CECT allowed the growth of species that could proliferate in acidic media, similar to the stream rich in phenolic compounds.

Aliquots from the ETP were cultured in liquid standard culture medium to promote growth of the present bacteria. After 3-4 days of growth, these grown cultures were refreshed and exposed to PS (up to $70 \mathrm{ppm}$ ), aimed at promoting growth of bacterial species that tolerated PS. Further, aliquots from these PS-added grown cultures were analyzed in solid culture medium for identifying the most abundant bacterial species which survived in presence of PS (see Materials and Methods, Section 2.2). Among the isolates grown on agar, those with the greatest potential for biodegradation of phenolic compounds were identified. Table 3 lists the names and main morphological features of the most abundant species isolated in Petri dishes containing standard medium (TSB or LB) supplemented with PS. In summary, six bacterial species were identified, of which the two predominant ones belonged to the Pseudomonas genus and one to Alcaligenes genus, with the genetic ability to metabolize hydrocarbons including phenol, according to published works $[11,29]$. These findings were in agreement with the results obtained from 
the massive sequencing analysis. Accordingly, P. putida and A. faecalis were proposed to form a bacterial consortium, and its potential to degrade phenolic components present in the PS was determined. The isolation of microorganisms in plates with a solid medium containing PS resulted in the following findings: (i) the used culture media was useful to preserve the microbial species present in the phenolic stream (TSB medium and LB medium added with PS); and (ii) we could isolate and identify the most abundant species possessing genetic resources to survive the presence of a complex mix of phenolic compounds.

Table 3. Bacterial species isolated from ETP samples. Main morphological features observed in plates, name of the isolates based on DNA sequencing data, and culture media for growth.

\begin{tabular}{ccc}
\hline Morphological Features & Bacterial Species & Culture Medium \\
\hline White colonies with halo around & Pseudomonas putida & TSB/LB \\
Colonies with no uniform edge & Aeromonas hydrophila & LB \\
Yellowish colonies of circular shape & Alcaligenes faecalis & LB \\
White colonies of circular shape & Aeromonas salmonicida & TSB/LB \\
Mushroom-shape white colonies & Pseudomonas parafulva & TSB \\
Orange colonies of circular shape & Exiguobacterium aurantiacum & LB \\
\hline
\end{tabular}

Before using P. putida and A. faecalis for biodegradation experiments, these bacterial strains were grown in the selected standard culture media to produce biomass that was subsequently used in biodegradation experiments. The so-formed consortium showed better growth in the LB and TSB medium (data not shown).

The biodegradation experiments were performed in synthetic culture media, essentially composed of water, aliquots of PS and, in some cases, nutrients, as described in the Materials and Methods section. The chemical composition of the culture medium containing the industrial by-product rich in phenolic compounds was determined following the procedure described in the Materials and Methods section. A representative chromatogram is shown in Figure 2, and the chemical composition is summarized in Table 1 (Materials and Methods section).

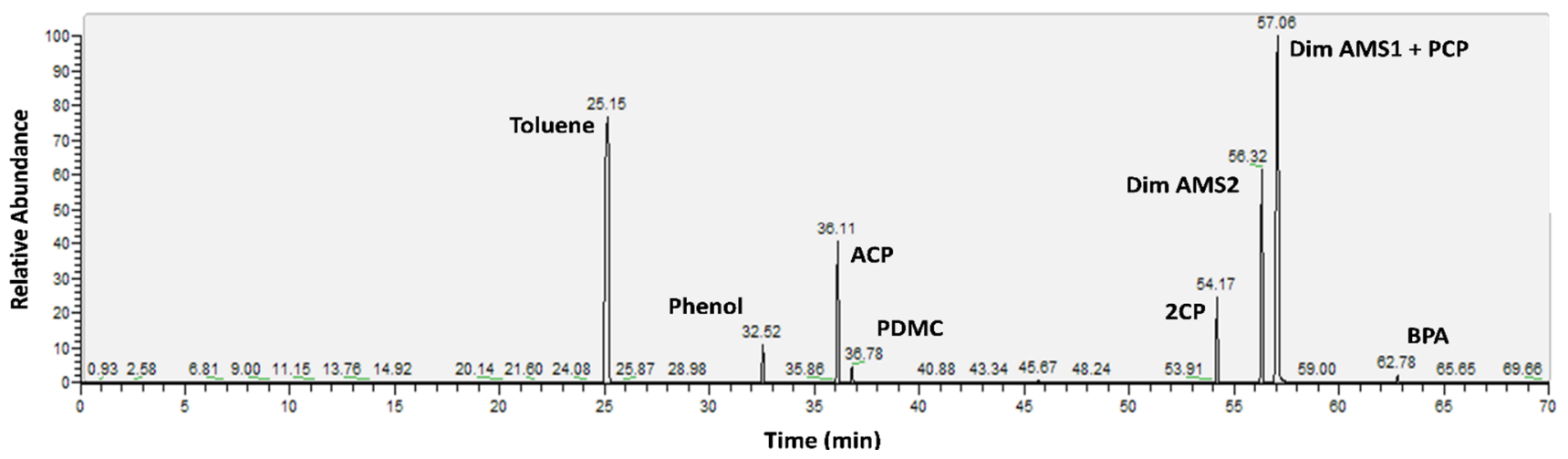

Figure 2. Representative chromatogram of chemical components present in the phenolic by-product stream (PS). The samples were diluted in toluene $(20: 80 \mathrm{w} / \mathrm{w})$ before chromatography. The details of the procedure are provided in the Materials and Methods section. ACP: acetophenone; PDMC: 2-phenyl-2-propanol; 2CP: o-cumylphenol; DimAMS1: 1,1'(1,3,3-trimethylprop-1-ene-1,3-diyl)dibenzene; DimAMS2: 2,4,diphenyl-4-methyl-1-pentene; PCP: 4-cumylphenol and BPA: BisphenolA.

The biodegradation assays were performed using bacterial cultures prepared in water to which aliquots of PS were added. According to earlier works, the levels of several phenolic compounds present in the PS, including phenol, AMS, and acetophenone, among others, are theoretically toxic to bacterial strains that are genetically able to degrade them [32].

The low availability of poorly soluble phenolic compounds to the selected bacterial strains in water limits biodegradation. To facilitate solubilization of phenolic compounds 
in aqueous culture media, the culture media with aliquots of industrial stream, without cells, was initially subjected to low-frequency sonication in a water bath. However, the use of sonication for preparing uniform mixtures of water-based culture media with added aliquots of PS requires several days (data not shown). Instead, ultra-turrax was used that resulted in a homogeneous and stable emulsion for days, without the need for heating or maintaining mechanical pressure over the homogeneous emulsion (Figure S1).

First, the tolerance of the two selected strains to phenolic compounds was determined. The culture medium for these experiments was composed of LB (water plus nutrients) and PS, and prepared as indicated above. The culture medium was inoculated with the selected bacterial strains, P. putida and A. faecalis. To achieve this, the bacterial consortium was grown in the referred culture medium containing increasing levels of PS: 70 ppm, $139 \mathrm{ppm}$, $280 \mathrm{ppm}$, and $700 \mathrm{ppm}$. The results are shown in Figure 3. As observed, the growth of the bacterial consortium in the presence of phenolic compounds always remained below that in the standard culture medium with no added PS. Interestingly, the consortium exhibited an increasing growth trend when grown on increasing concentrations of PS up to $280 \mathrm{ppm}$, decreasing in the culture supplemented with $700 \mathrm{ppm}$. These results pointed to the minimum concentrations of PS that might inhibit the growth, roughly between 300 and 700 ppm. In addition, this would be the inhibitory concentration for cultures with the maximum OD values around 2, meaning there would still be room for increasing the PS level in the culture media. This process feature should be optimized at a pilot scale.

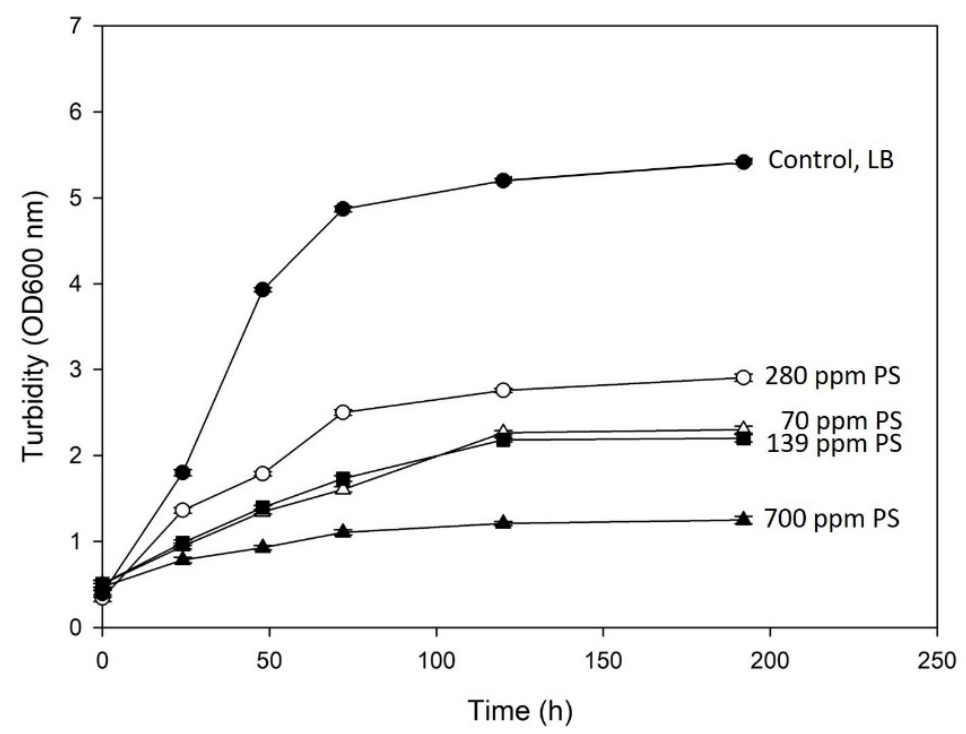

Figure 3. Growth curves were obtained from cultures of the bacterial consortium in the LB medium supplemented with different concentrations of PS. A culture in LB standard medium with no added PS served as the control. The numbers on the right side of each curve indicate the concentration (ppm) of PS added to each culture. The curve for each condition is the average of three replicates. Details of the LB standard culture medium preparation and cultivation procedure details are provided in the Materials and Methods section.

We tried to adapt the bacterial consortium to increasing concentrations of phenolic compounds by progressive addition of PS to cultures in the exponential phase (optical density was measured at $660 \mathrm{~nm}$ ). The consortium was finally adapted to grow in the culture medium supplemented with 700 ppm PS. It achieved a maximum growth factor of 1 after 5 days of growth, which was calculated as the maximum increment in the culture optical density at 660 ( 0.55 unit) divided by the initial value ( 0.55 unit, data in Figure 4$)$. The growth factor calculated for non-adapted cultures subjected to the same physicochemical conditions was roughly half of this value (Figure 3). This result could be attributed to the genetic resources of bacterial strains in the consortium that assisted in the metabolism 
of organic compounds present in the industrial effluent. The adapted consortium was preserved for further use in biodegradation assays.

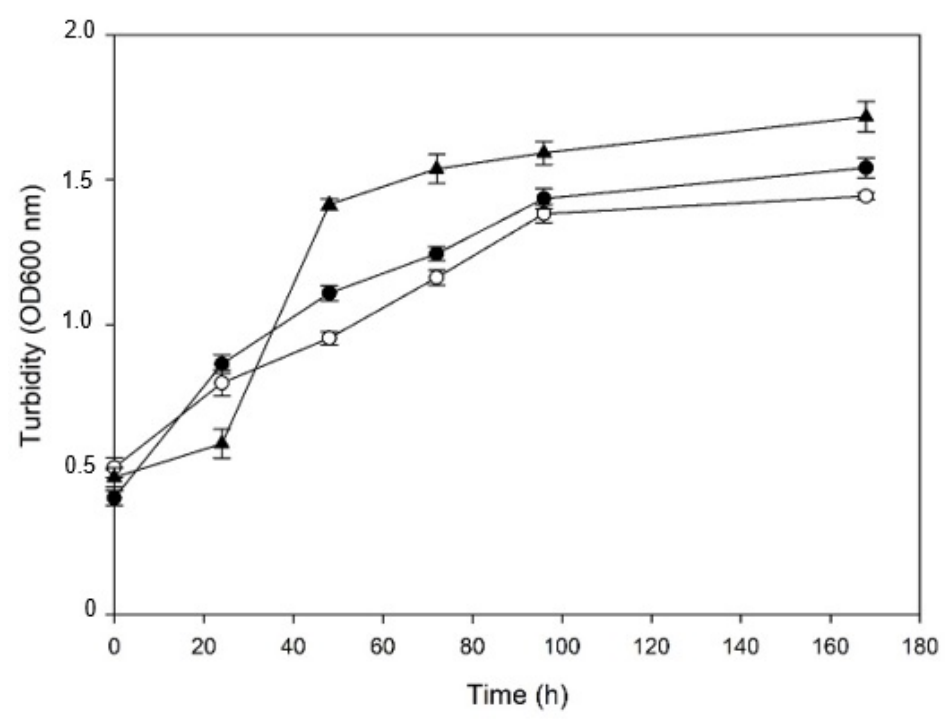

Figure 4. Growth curves were obtained from cultures of the bacterial consortium in different media. The bacterial consortium was grown in the following media: (open circles) LB culture medium prepared in deionized water +700 ppm PS; (solid circles) LB medium prepared in TW +700 ppm PS; (solid triangles) TW +700 ppm PS. The curve for each condition is obtained by calculating the average of three replicates. Details of the LB standard culture medium preparation and the cultivation procedure are given in the Materials and Methods section.

\subsection{Towards Process Conditions: Assessment of a Close-to-Process Culture Medium}

The process studied and discussed here would meet some of the principles of the circular economy frame, reflected in the following facts: (i) the bacterial consortium used here consisted of local species isolated from the ETP of the chemical factory, instead of recruiting other strains from external sources with uncertain long-term adaptation capabilities to the complex phenolic mix and which, in addition, would affect the stabilized biodiversity of the ETP; (ii) water from a wastewater treatment plant was reused, which would be used as a base ingredient for the culture medium for the consortium, and (iii) a part of the carbon from the phenolic compounds was recycled into biomass; because these phenolic compounds are the only carbon sources available to the bacterial consortium for growth, it avoids additional costs derived from adding other organic compounds commonly used by bacteria.

The application of the bacterial consortium for biodegradation of PS at an industrial scale would require a culture medium that is easily prepared and is economically feasible. According to the two latter premises [(ii) and (iii)], the next question to be answered in this work was whether the selected bacterial strains could grow in water from a wastewater treatment plant and use phenolic compounds as the only carbon source available. Thus, the following culture media were prepared to evaluate the potential of the bacterial consortium to grow: (i) treated water (TW) from the ETP of the factory; (ii) TW from the ETP added with LB nutrients (rich in organic carbon); and (iii) LB medium prepared in deionized water as a positive control, expected to yield the maximum growth in the presence of the added phenolic compounds. All these media were added at 700 ppm PS, rich in phenolic compounds, and were further inoculated with the bacterial consortium previously adapted to grow at the indicated PS concentration. The appearance of these cultures is shown in Figure S2. The growth trends in these cultures are shown in Figure 4.

As inferred from the data shown in Figure 4, the performance of the consortium in the culture media supplemented with standard organic nutrients (LB medium) plus PS roughly equaled that of culture media composed of TW from the ETP supplemented with PS as the 
only carbon source. Moreover, the bacterial growth in TW plus 700 ppm PS culture showed a slightly higher growth rate than the other two cultures prepared in LB standard medium that contains organic nutrients. The maximum OD values were substantially lower than those obtained for control cultures (Figure 3), which should be a direct consequence of the toxicity of phenolic compounds to the cells, reducing the growth by roughly $75 \%$ in terms of OD. Interestingly, these results suggest that reduced carbon sources commonly used for bacterial growth, similar to those contained in the LB medium, would not be used by the bacterial consortium when PS (700 ppm) is added to the medium. The growth is noticeably reduced by roughly $75 \%$ (open circles in the figure) compared to that for the control culture shown in Figure 3. In addition, the results revealed that phenolic carbon was used catabolically to obtain metabolic energy for growth (solid triangles).

We suggest that co-metabolism might not be occurring in the complex mix of phenolic compounds. This might be assessed by determining the time-course consumption of phenolic compounds present in the cultures added with PS. The bacterial consortium adapted to PS would genetically prioritize reducing the potential toxicity of the complex phenolic mix by degrading them through specific biochemical routes instead of boosting growth-linked metabolic cell processes based on using metabolically efficient carbon sources. In addition, the results suggest the use of treated water from the ETP as a suitable resource to prepare the cultivation media, from which the bacterial consortium can actively biodegrade the phenolic compounds of the added PS. Thus, the whole bioremediation process would be entirely built up by internal components arising from the industrial process and in coherence with the basic principles of the circular economy.

Once adapted to the presence of $700 \mathrm{ppm}$ of PS and able to grow in TW supplemented with PS, the consortium was subsequently subjected to increased concentrations of PS (1048 ppm and 1748 ppm) while growing in a liquid medium based on the TW. The bacterial consortium could grow in all emulsions prepared with TW and the increased concentrations of PS. The results are shown in Figure 5. The bacterial consortium grew rapidly in the medium with low PS concentration (700 ppm), whereas the lowest growth was observed in the medium added with 1748 ppm PS. Nevertheless, there were only small differences in the growth between the cultures added with the three major PS concentrations in terms of maximum OD at 600. The growth in all cultures increased with the use of bacterial consortium previously adapted to $700 \mathrm{ppm}$ PS, which might explain the tolerance of the bacterial consortium to grow at PS concentrations more than two-fold higher than $700 \mathrm{ppm}$.

\subsection{Performance of Semicontinuous Cultures of the Bacterial Consortium for Biodegradation of a Complex Mix of Phenolic Compounds (PS)}

The potential application of the consortium to biodegrade the highest levels of PS (Figure 5) would depend not only on its tolerance to just one cycle exposure to given PS levels, but also to continuous dilution cycles of the culture under that PS concentration. Based on this, we next analyzed the adaptation capacity of the consortium to grow at an approximately constant rate for several four repeated dilution cycles, and each of the cultures subjected to a given concentration of PS. Process details are given in the Materials and Methods section. The results of these experiments are shown in Figure 6. As observed, all cultures showed roughly a constant growth rate throughout the four repeated dilution cycles at a given concentration of PS. This growth rate decreased with the PS concentration the bacteria were exposed to. Thus, the culture under $700 \mathrm{ppm}$ showed the highest growth trends of three cultures, the four repeated growth cycles being completed in about six days, whereas cultures subjected to higher PS levels (up to $1398 \mathrm{ppm}$ ) required twice this time (half growth rate values, roughly) to complete four repeated growth cycles. A fourth culture added with 1748 ppm PS was also included in the experiment, although the growth was inhibited after the first growth cycle, which could be due to the toxicity exerted by the high levels of phenolic compounds. 


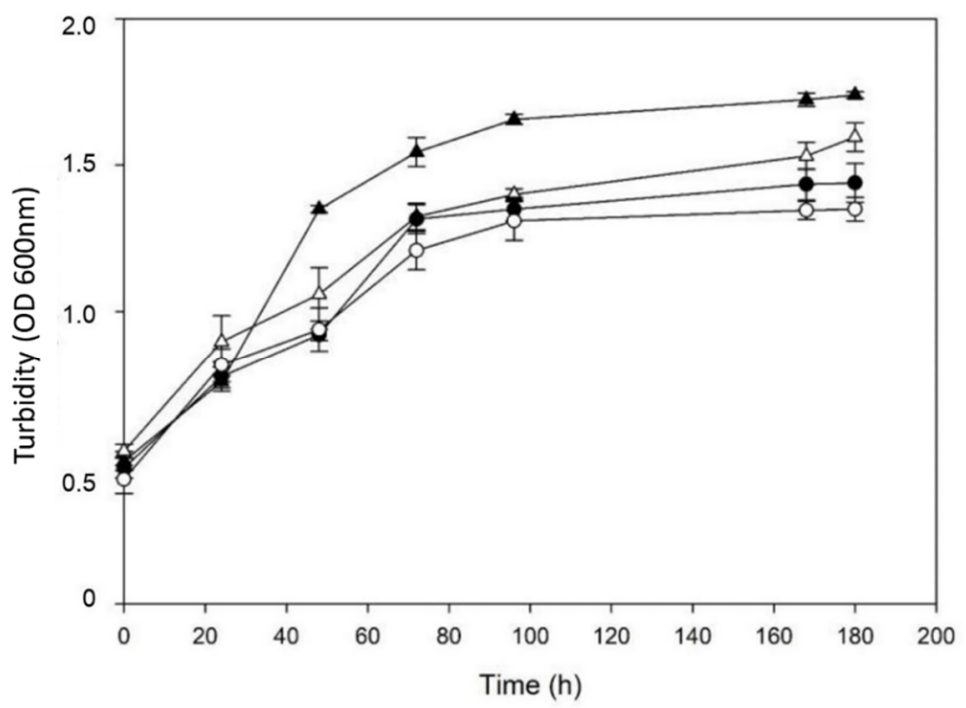

Figure 5. Growth curves were obtained from cultures of the bacterial consortium growing in media composed of TW and different concentrations of PS. The bacterial consortium was grown in TW added with the following PS concentrations: (solid triangles) 700 ppm, (open triangles) 1048 ppm, (solid circles) 1398 ppm, and (open circles) 1748 ppm. The curve for each condition is obtained by calculating the average of three replicates. The details of the cultivation procedure are given in the Materials and Methods section.

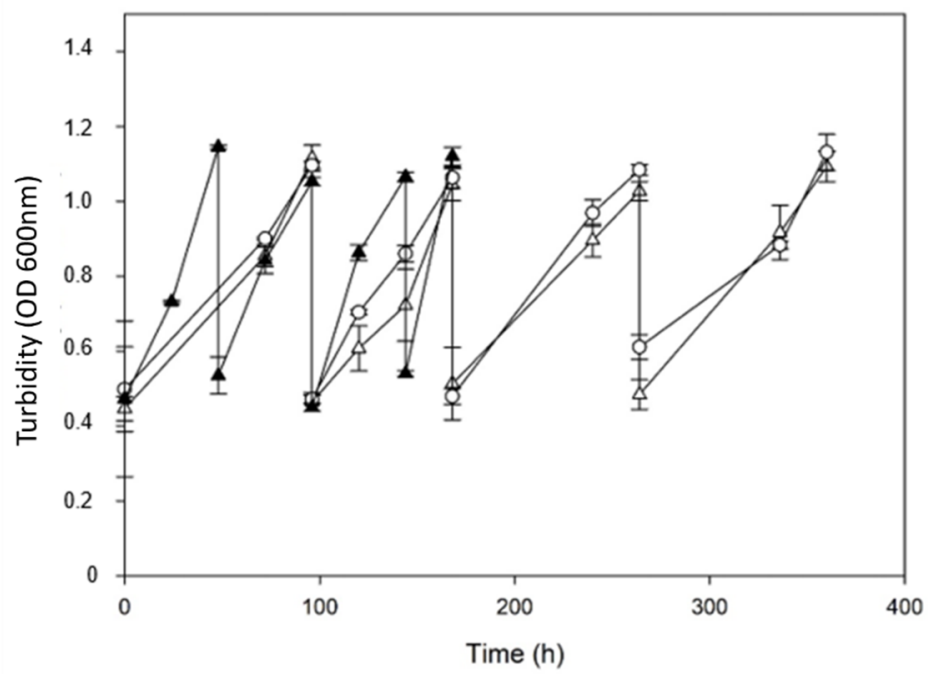

Figure 6. Repeated batch cultures of the bacterial consortium in TW to which PS was added at different concentrations. The bacterial consortium was grown in TW added with the following PS concentrations: (solid triangles) 700 ppm; (open triangles) 1048 ppm; and (open circles) 1398 ppm. The curve for each condition was obtained by calculating the average of three replicates. The details of the cultivation procedure are given in the Materials and Methods section.

The bacterial consortium cell density affects its tolerance to the concentration of phenolic compounds because the level of these toxic molecules a single cell is exposed to will depend on the active biomass concentration of the culture. Indeed, the phenol degradation rates in bacterial cultures has been proven to depend on the initial biomass concentration and growth dynamics of the phenol-degrading strains used [32]. Thus, the biomass concentration plays a relevant role in the parameters design for the optimal performance of a scaled process. In addition, the phenol degradation rate also depends on the presence of other carbon sources that can tightly regulate the expression of key genes of the phenol degradation pathway at transcriptional level. This was demonstrated 
in cultures of Rhodococcus erythropolis and Rhodococcus jostii, in an elegant work published by Szököl et al. [33], which reported that while phenol induces gene clusters involved in the orthocleavage pathway of phenol degradation in the referred Rhodococcus species, the presence of other carbon sources can repress the expression of those phenol degradation gene clusters. Moreover, analysis of the transcriptional regulation of two similar phenol degradation gene clusters from $R$. jostii RHA1 by various substrates showed that the type of carbon catabolite repression and the temporal transcriptional pattern are different in each of the clusters analyzed [33]. Thus, the phenol and phenolic compounds degradation induction patterns and degradation rates, in a complex mixture of various organic compounds, can show great variability as a function of each compound's influence on the activation and repression patterns of key genes. No general trends can therefore be inferred to explain phenol degradation in complex organic matrices.

The eventual degradation of phenolic compounds in bacterial cultures with added PS aliquots was determined in samples (Figure 5) obtained on day 7 of the experiment using the analytical procedures described in the Materials and Methods section. The results are shown in Table 4, together with the initial and final concentrations of different phenolic compounds.

Table 4. Degradation rates of compounds in emulsions formed by bacterial cultures and different quantities of phenolic industrial by-product stream. The following data are given: concentrations of phenolic by-product stream added to the cultures (PS), expressed in ppm, and degradation rate (DGR, \% of the initial concentration). The DGR was obtained for each phenolic compound based on its remaining content in the culture after 7 days. The content of each compound in the PS is given in Table 2. Each value corresponds to the average of three replicates.

\begin{tabular}{ccccc}
\hline PS & 710 $\mathbf{~ p m ~}$ & $\mathbf{1 0 7 0} \mathbf{~ p p m}$ & $\mathbf{1 4 2 0} \mathbf{~ p m}$ & $\mathbf{1 7 8 0} \mathbf{p p m}$ \\
\hline DGR (\%) & DGR (\%) & DGR (\%) & DGR (\%) \\
\hline Phenol & 100 & 98.2 & 98.1 & 97.7 \\
ACP & 99.8 & 80.8 & 95.9 & 95.3 \\
PMDC & - & 9.6 & - & 23.2 \\
2CP & 45.2 & 79.5 & 73 & 60.8 \\
DiAMS1 & 91.5 & 91.5 & 90.8 & 92.8 \\
PCP & - & 57.8 & 47.4 & 36.4 \\
\hline
\end{tabular}

These data revealed the following trends: (i) Most of the phenolic compounds present in the cultures were degraded to a large extent, on average about $75 \%$ of the total concentration of phenolic compounds. (ii) No general trend of the degradation rates can be inferred from the data in Table 4, though a slight decrease in degradation rate can be observed at a higher concentration of certain compounds (phenol, $\mathrm{CP}, \mathrm{PCP}$ ), although not proportionally to that concentration. The former observation is in good agreement with the fact that most of the phenolic compounds from the industrial by-product stream could be degraded to a certain level, resulting in the net bacterial growth derived from a catabolically efficient management of those compounds. The remaining concentrations of phenolic compounds were related to the limited biomass concentration used at the laboratory scale experimental set-up and the expected toxicity produced by phenolic compounds, whose levels exceeded those inhibiting bacterial growth, in addition to the possible synergistic toxic effect arising from the simultaneous presence of several phenolic compounds.

Phenol was one of the simplest compounds in the studied stream. The biochemical biodegradation pathway of phenol in the aerobic atmosphere has been described for a wide number of microorganisms, including Pseudomonas species. In addition to speciesdependent differences, the pathway involves the cleavage of the aromatic ring through successive enzyme-mediated carbon oxidations and the use of molecular oxygen [12,34,35], resulting in metabolic intermediates such as citrate and aconitate, which enter the TCA cycle to finally yield metabolic energy. Bacterial strains genetically capable of completely mineralizing phenol in 3 to 4 days show high rates of biodegradation, ranging from 0.5 to 
$1.6 \mathrm{~g} / \mathrm{L}[12,32]$ if tested in cultures with optimal nutritional and physicochemical growth conditions and using phenol as the only carbon source, which is not usually the case in real conditions. This bacterial capability is mostly limited if other phenolic compounds are present in the medium, thereby decreasing the tolerance of the bacterial consortium to organic compounds.

The phenolic compounds by-product stream contains acetophenone. Acetophenone toxicity has been reported at concentrations in the range of 0.4 to $30 \mathrm{mM}$ [36-38]. This concentration is roughly 4 -fold higher than that of acetophenone concentration present in the bacterial consortium cultures when added with the maximum concentration they can tolerate. Thus, theoretically, acetophenone should be partly degraded rather than exerting toxicity to the bacterial species. The aerobic degradation of acetophenone is known for a long time and was described to occur through the Baeyer-Villiger oxidation pathway forming (chloro)phenyl-acetate esters [39] catalyzed by oxygenases [40]. Acetophenone is a key intermediate of anaerobic ethylbenzene metabolism; it can be degraded aerobically via a complex of ATP-dependent acetophenone carboxylase and a benzoylacetate-CoA ligase, whose genes are organized in an operon expressed in the presence of the substrate [38]. The product is subsequently degraded, producing energy for bacterial growth. Accordingly, we speculate this could be the degradation pathway followed by acetophenone in the aerobic process studied in this work mediated by Pseudomonas and Alcaligenes, which would be consumed by the bacterial consortium (Table 4).

The industrial effluent used in this study also contained 2- and 4-cumylphenols. These phenolic compounds are structurally more complex compared to phenol and acetophenone (Table 1). Unlike the natural ability of specific bacterial strains to metabolize the latter molecules, the literature reports no strains that can degrade cumylphenols, except for one degrading 4-cumylphenol [41] — the first report demonstrating that a microorganism can eliminate 4-cumylphenol. The study referred to specific fungal strains as suitable microorganisms to at least partially decompose the more complex structure of the cumylphenol into less toxic molecules, as a sort of self-defense biochemical mechanism. According to Janicki et al. [41], instead of being mineralized to $\mathrm{CO}_{2}$ and $\mathrm{H}_{2} \mathrm{O}$ via catabolic degradation under aerobic conditions, the degradation of cumylphenol involves numerous biotransformation steps catalyzed by fungal enzymes to form chemical intermediates with less harmful effects than the parent compound. This conclusion was obtained by analyzing the harmful effects of intermediates in Artemia franciscana and Daphnia magna, which were used as bioindicators.

According to the latter, the biodegradation activity demonstrated in the present work for 2- and 4-cumylphenols could be a sign of genetic capabilities of the bacterial consortium to transform the mentioned molecules into chemical intermediates, causing less physiological damage, as the bacterial consortium has adapted to the presence of the above-cited compounds (Table 4). This would therefore be the first time that biodegradation capabilities for 2- and 4-cumylphenols are reported to be expressed by bacterial strainsP. putida and A. faecalis.

Alpha-methylstyrene is also present in the PS at a concentration of roughly $21 \%$ (Table 1). Although the number of published studies specifically focusing on the biodegradation of alpha-methylstyrene is scarce, some of them describe in detail a possible metabolic pathway for this compound [42-44]. The latter study describes two possible oxidation catabolic routes for alpha-metylstyrene using a P. aeruginosa strain. The first route involves enzymatically catalyzed hydroxylation of an aromatic ring, resulting in metabolic products derived from 1-isopropenyl-6-cyclohexene and 3-isopropyl-catechol, which are later metabolized to keto-acids. The second route involves the oxidation of $\alpha$-phenylpropionic acid and 4-methylbenzene alcohol to produce acetophenone [44].

The degradation activity shown in Table 4 is attributed primarily to the biochemical action of microbial consortium on the compounds present in the PS aliquots added to the cultures. Nevertheless, chemical degradation might also be occurring under the physicochemical conditions of the heterogeneous mixture of living bacteria and organic 
compounds, which remain for a relatively long time in an aerobic environment and mild temperature conditions. This can favor chemically driven oxidation of carbon and thus can reduce the toxic compounds. Therefore, samples from the emulsion with $1420 \mathrm{ppm}$ PS were analyzed using the metabolomic approach described in the Materials and Methods section to identify as many molecules as possible in the emulsion, outside the cells, which could arise from any chemical and/or biological degrading activity occurring in the emulsion during the cultivation period of the bacterial consortium. Table 5 compiles a list of compounds present in the supernatant of the culture with $1420 \mathrm{ppm}$ of added PS (Figure 5).

Table 5. Mass spectral data and possible origin of molecules present in the emulsions formed by bacterial cultures and phenolic industrial by-product stream (1420 ppm PS) after 7 days of incubation.

\begin{tabular}{|c|c|c|c|c|}
\hline Metabolite & Retention Time (min) & Formula & Molecular Ion $(\mathrm{m} / \mathrm{z})$ & Genesis \\
\hline 2-Methoxynaphthalene & 5.168 & $\mathrm{C}_{11} \mathrm{H}_{10} \mathrm{O}$ & 159.08 & Chemical synthesis \\
\hline Methyl $\beta$-phenylglycidate & - & $\mathrm{C}_{12} \mathrm{H}_{14} \mathrm{O}_{3}$ & - & Possibly from DimAMS degradation \\
\hline Linalyl benzoate & 6.341 & $\mathrm{C}_{17} \mathrm{H}_{22} \mathrm{O}_{2}$ & 259.16 & Possibly from DimAMS degradation \\
\hline 10-Eicosane & 25.639 & $\mathrm{C}_{20} \mathrm{H}_{42}$ & 298.34 & Chemical synthesis \\
\hline Stearamide & 32.084 & $\mathrm{C}_{22} \mathrm{H}_{45} \mathrm{NO}_{2}$ & 284.29 & Chemical synthesis \\
\hline Cinitapride & 26.818 & $\mathrm{C}_{21} \mathrm{H}_{30} \mathrm{~N}_{4} \mathrm{O}_{4}$ & 403.23 & Chemical synthesis \\
\hline Doxazosin & 30.077 & $\mathrm{C}_{23} \mathrm{H}_{25} \mathrm{~N}_{5} \mathrm{O}_{5}$ & 469.21 & Chemical synthesis \\
\hline Geranylgeraniol & - & $\mathrm{C}_{20} \mathrm{H}_{34} \mathrm{O}$ & - & $\begin{array}{l}\text { Possibly from } \\
\text { isoprenoid-derivatives degradation }\end{array}$ \\
\hline Rifamycin & 33.439 & $\mathrm{C}_{39} \mathrm{H}_{49} \mathrm{NO}_{14}$ & 720.30 & Water contaminant \\
\hline Acetamide & 4.32 & $\mathrm{C}_{2} \mathrm{H}_{5} \mathrm{NO}$ & 59.07 & Chemical origin \\
\hline Ganoderenic acid A & 29.626 & $\mathrm{C}_{30} \mathrm{H}_{44} \mathrm{O}_{7}$ & 537.28 & Biological origin \\
\hline Hexadecanoic acid & 10.78 & $\mathrm{C}_{16} \mathrm{H}_{32} \mathrm{O}_{2}$ & 256.42 & Fatty acid in membrane lipids \\
\hline Urea & 4.65 & $\mathrm{CH}_{4} \mathrm{~N}_{2} \mathrm{O}$ & 60.06 & Possible bacterial origin \\
\hline Glycerol & 92.09 & $\mathrm{C}_{3} \mathrm{H}_{8} \mathrm{O}_{3}$ & 4.83 & TAG hydrolysis, biological origin \\
\hline Benzoic & 7.18 & $\mathrm{C}_{7} \mathrm{H}_{6} \mathrm{O}_{2}$ & 122.12 & $\begin{array}{c}\beta \text {-oxidation of fatty acids in } \\
\text { bacterial cells }\end{array}$ \\
\hline
\end{tabular}

Results shown in Table 5 aim to distinguish between compounds that might have originated as a consequence of whatever chemical degradation process occurring in the emulsion during the cultivation period, from those that might have derived from bacterial metabolism or degradation of cell structures. These compounds are believed to be biological in nature and might have been released by the cells or been partially extracted by any of the phenolic compounds present in the medium. Based on their possible origin, the molecules listed in Table 5 could be grouped into the following clusters:

(a) Molecules generated by degradation: This group comprises the first (methyl $\beta$ phenylglycidate) and the second (linalyl benzoate) molecules (Table 5). Methyl $\beta$ phenylglycidate and linalyl benzoate originated from biological and/or chemical degradation of phenolic compounds originally present in the industrial effluent. The chemical structure of these molecules suggests that they might originate from the mentioned processes. This hypothesis finds scientific support in the literature and is discussed below.

(b) Molecules of biological synthesis: This group comprises several molecules, including geranylgeraniol, hexadecanoic acid, glycerol, and benzoic acid, among others. These originate from cell metabolism and are further released into the medium or partially extracted from the cells by any of the phenolic compounds present in the medium.

Regarding the first cluster, the biological oxidation of styrene to yield styrene-epoxidated derivatives has been described in specific bacterial spp. For example, P. putida strain was found to possess an oxidative mechanism based on a membrane-located monooxygenase system, namely xylene oxygenase, which catalyzes the oxidation of styrene to styrene epoxide [42,43]. The membrane-bound monooxygenase systems are common in bacteria and degrade hydrocarbon compounds; the oxidation of terminal carbons is the first 
biochemical step in the oxidative metabolic pathway to mineralize or partly biodegrade such compounds $[45,46]$. E. coli has been genetically engineered and transformed with $P$. putida genes to produce epoxides from methylstyrene [47]. The latter study proved the stereoselective epoxidation of cis- $\beta$-methylstyrene using cytochrome P-450 from P. putida. Interestingly, the biochemical epoxidation of methylstyrene catalyzed by alkene monooxygenase has been hypothesized to be a bacterial biochemical mechanism to reduce toxic effects of aromatic compounds present in the medium, as a result of the biotransformation of methylstyrene into less harmful compounds [43]. This is consistent with the results obtained from the metabolomic approach of our work, which studied the reduction in the concentration of methylstyrene compounds in the presence of the bacterial consortium under active growth, eventually resulting in the secretion of methylstyrene epoxide in the culture medium. The mentioned biochemical mechanism of methylstyrene epoxidation might, in addition, find attractive applications for the production of fine chemicals that are difficult to synthesize [42,43].

Methylstyrene can also be chemically epoxidized. For instance, Cu-mediated epoxidation of terminal alkene containing allylic hydrogen atoms has been proved efficient for trans-methylstyrene on $\mathrm{Cu}$ [48]. The same chemical oxidation process has been reported for alfa-methylstyrene in an acidic medium (peracetic) and in the presence of methylene chloride [49]. Accordingly, epoxidation is favored at low $\mathrm{pH}$ and in the presence of efficient catalysts. In our work, the chemical conditions of the culture medium differed from those required for an efficient epoxidation process, as the medium lacked metal or organic catalysts, and $\mathrm{pH}$ was not acidic. Nevertheless, based on the slightly acidic $\mathrm{pH}$ of the medium, the presence of trace levels of $\mathrm{Cu}$ (II) and Mn (II) (among other metal ions), and the long-term bacterial incubation process, which takes several days, we speculate the occurrence of very low rates of catalytic epoxidation of alfa-methyl styrene occur, resulting in the production of very low levels of the epoxide.

In relation to the second group of molecules, molecules of biological synthesis, we identified the following using metabolomic analytical techniques: geranylgeraniol, hexadecanoic acid, benzoic acid, glycerol, and urea (in the order of decreasing number of carbon atoms). From latter molecules, geranylgeraniol and hexanoic acid were derived from the primary lipid anabolic pathways in prokaryotic and eukaryotic microorganisms. Geranylgeraniol or geranyl-related biological structure might originate from the carotenoid biosynthesis pathway, which initiates from smaller precursors produced by the glycolytic pathway [50]. Although carotenoid production is less common in non-photosynthetic bacteria than in photosynthetic microorganisms, certain bacterial strains, such as Pseudomonas putida, synthesize and accumulate low content of carotenoids [51]. P. putida has been found to possess a cluster of six genes encoding the carotenoid production pathway similar to other carotenoid-producing bacteria that belong to the $\alpha$-proteobacteria or $\gamma$-proteobacteria class [52]. The induction of carotenoid production in carotenoid-producing bacteria can be triggered, among other conditions, by sequential nutrition starvation or several stress factors [51]. The bacterial consortium selected in this study was subjected to limiting growth conditions when incubated in the presence of a phenolic by-product stream, such as nitrogen and phosphorus deficiency. These stress conditions induce carotenoid biosynthesis and can explain the detection of carotenoid precursors in the culture medium.

Interestingly, the above-discussed trends in biological and chemical degradation of molecules in the culture medium are not specific to biological and chemical systems studied in the present work. On the contrary, the basic concepts underlying the degradation of phenolic compounds could be useful to understand the degradation of similar complex mixtures of phenolic compounds using suitable bacterial strains.

\section{Conclusions}

This work demonstrates that current molecular and metabolomic tools can be combined to obtain detailed scientific insights, from a complex biological and chemical perspective, into bacterial activity in a phenolic compound-containing stream and using the 
obtained information to design biodegradation processes. The results from massive sequencing of liquid samples from the ETP were useful in selecting bacterial species with specific catabolic capabilities to degrade complex mixtures of phenolic compounds from real industrial streams. The metabolomic approach revealed that the bacterial catabolic activity might partly be expressed to reduce the toxicity of certain phenolic compounds by transforming them into less harmful molecules to bacteria. In addition, metabolomics demonstrated the presence of catabolism-associated bacterial products, small organic molecules whose further use might be investigated specifically in each study case. Overall, the concepts underlying the degradation of phenolic compounds could be applied to understand similar bioprocesses metabolized by suitable bacterial strains.

Supplementary Materials: The following are available online at https:/ / www.mdpi.com/article / 10.3390/pr9111964/s1, Figure S1: Emulsion of phenolic industrial by-product and culture bacterial culture medium, Figure S2: Cultures of the bacterial consortium in the emulsions formed.

Author Contributions: Conceptualization, J.L., J.F., T.G.-B., J.-L.G.-A., C.V.; methodology, A.B., G.R.-M., J.-L.F., M.L.; validation, A.B., G.R.-M., M.L.; formal analysis, M.L., J.L., T.G.-B., J.-L.F., C.V.; investigation, A.B., G.R.-M., M.L.; resources, J.L., J.F., M.C., T.G.-B., J.-L.G.-A., C.V.; data curation, A.B., G.R.-M.; writing—original draft preparation, A.B., G.R.-M., T.G.-B., C.V.; writing-review and editing, all authors; supervision, J.-L.F., M.C.; project administration, M.L., M.C., T.G.-B. All authors have read and agreed to the published version of the manuscript. Alejandra Bartolomé and Gema Rodríguez contributed equally to this work in the quality of first author.

Funding: The research activities shown in this work were funded by CEPSA S.A.U. and Technological Corporation of Andalusia (CTA, Grant number 19/1002).

Institutional Review Board Statement: Not applicable.

Informed Consent Statement: Not applicable.

Data Availability Statement: Data sharing not applicable. No new data were created or analyzed in this study. Data sharing is not applicable to this article.

Conflicts of Interest: The authors declare no conflict of interest.

\section{References}

1. Busca, G.; Berardinelli, S.; Resini, C.; Arrighi, L. Technologies for the removal of phenol from fluid streams: A short review of recent developments. J. Hazard. Mater. 2008, 160, 265-288. [CrossRef]

2. Pal, P.; Kumar, R. Treatment of coke wastewater: A critical review for developing sustainable management strategies. Separ. Purif. Rev. 2014, 43, 89-123. [CrossRef]

3. Cetinkaya, A.Y.; Ozdemir, O.K. Phenol removal from synthetic solution using low pressure membranes coated with graphene oxide and carbon. Chem. Pap. 2018, 72, 327-335. [CrossRef]

4. Michałowicz, J.; Duda, W. Phenols sources and toxicity. J. Environ. Stud. 2007, 16, 347-362.

5. Dayana-Priyadharshini, S.; Bakthavatsalam, A.K. A comparative study on growth and degradation behavior of $C$. pyrenoidosa on synthetic phenol and phenolic wastewater of a coal gasification plant. J. Environ. Chem. Eng. 2019, 7, 103079. [CrossRef]

6. Gao, M.; Diao, M.H.; Yuan, S.; Wang, Y.K.; Xu, H.; Wang, X.H. Effects of phenol on physicochemical properties and treatment performances of partial nitrifying granules in sequencing batch reactors. Biotechnol. Rep. 2017, 13, 13-18. [CrossRef]

7. Pop, C.E.; Draga, S.; Măciucă, R.; Niță, R.; Crăciun, N.; Wolff, R. Bisphenol A Effects in Aqueous Environment on Lemna minor. Processes 2021, 9, 1512. [CrossRef]

8. Rucká, L.; Nešvera, J.; Pátek, M. Biodegradation of phenol and its derivatives by engineered bacteria: Current knowledge and perspectives. World J. Microbiol. Biotechnol. 2017, 33, 174. [CrossRef] [PubMed]

9. Tomei, M.C.; Mosca-Angelucci, D.; Clagnan, E.; Brusettil, L. Anaerobic biodegradation of phenol in wastewater treatment: Achievements and limits. Appl. Microbiol. Biotechnol. 2021, 105, 2195-2224. [CrossRef]

10. Kaczorek, E.; Smułek, W. Special Issue "Study of Biodegradation and Bioremediation". Processes 2021, 9, 1130. [CrossRef]

11. Barman, S.R.; Banerjee, P.; Mukhopadhayay, A.; Das, P. Biodegradation of acenapthene and naphthalene by Pseudomonas mendocina: Process optimization, and toxicity evaluation. J. Environ. Chem. Eng. 2017, 5, 4803-4812. [CrossRef]

12. Barik, M.; Das, C.P.; Verma, A.K.; Sahoo, S.; Sahoo, N.K. Metabolic profiling of phenol biodegradation by an indigenous Rhodococcus pyridinivorans strain PDB9T N-1 isolated from paper pulp wastewater. Int. Biodeter. Biodegrad. 2021, 158, 105168. [CrossRef]

13. Kong, L.; Gao, Y.; Zhou, Q.; Zhao, X.; Sun, Z. Biochar accelerates PAHs biodegradation in petroleum-polluted soil by biostimulation strategy. J. Hazard. Mater. 2018, 343, 276-284. [CrossRef] 
14. Liang, X.; Guo, C.; Liao, C.; Liu, S.; Wick, L.Y.; Peng, D.; Yi, X.; Lu, G.; Yin, H.; Lin, Z.; et al. Drivers and applications of integrated clean-up technologies for surfactant-enhanced remediation of environments contaminated with polycyclic aromatic hydrocarbons (PAHs). Environ. Pollut. 2017, 225, 129-140. [CrossRef]

15. Nybo, S.E.; Lamberts, J.T. Integrated use of LC/MS/MS and LC/Q-TOF/MS targeted metabolomics with automated label-free microscopy for quantification of purine metabolites in cultured mammalian cells. Purinergic Signal. 2019, 15, 17-25. [CrossRef]

16. Begley, P.; Francis-McIntyre, S.; Dunn, W.B.; Broadhurst, D.I.; Halsall, A.; Tseng, A.; Knowles, J.; Consortium, H.; Goodacre, R.; Kell, D.B. Development and Performance of a Gas Chromatography-Time-of-Flight Mass Spectrometry Analysis for Large-Scale Nontargeted Metabolomic Studies of Human Serum. Anal. Chem. 2009, 81, 7038-7046. [CrossRef]

17. Jagiello, Z.; López-García, A.; Aguirre, J.I.; Dylewski, L.Z. Distance to landfill and human activities affects the debris incorporation into the white stork nests in urbanized landscape in central Spain. Environ. Sci. Pollut. Res. 2020, 27, 30893-30898. [CrossRef] [PubMed]

18. Navarrete, A.; Rupérez, F.J.; Mendes, T.O.; Pérez-Rial, S.; Girón-Martínez, A.; Terrón-Expósito, R.; Díaz-Gil, J.J.; Peces-Barba, G.; Barbas, C.; García, A. A metabolomic approach shows sphingosine 1-phosphate and lysophospholipids as mediators of the therapeutic effect of liver growth factor in emphysema. J. Pharm. Biomed. Anal. 2017, 139, 238-246. [CrossRef] [PubMed]

19. Annadurai, G.; Juang, R.S.; Lee, D.J. Microbiological degradation of phenol using mixed liquors of Pseudomonas putida and activated sludge. Waste Manag. 2002, 22, 703-710. [CrossRef]

20. Lin, Y.H.; Gu, Y.J. Biodegradation Kinetic Studies of Phenol and $p$-Cresol in a Batch and Continuous Stirred-Tank Bioreactor with Pseudomonas putida ATCC 17484 Cells. Processes 2021, 9, 133. [CrossRef]

21. Jiang, Y.; Wen, J.; Bai, J.; Jia, X.; Hu, Z. Biodegradation of phenol at high initial concentration by Alcaligenes faecalis. J. Hazard. Mater. 2007, 147, 672-676. [CrossRef] [PubMed]

22. Nair, C.I.; Jayachandran, K.; Shashidhar, S. Biodegradation of phenol. Afr. J. Biotechnol. 2008, 7, 4951-4958. [CrossRef]

23. Sun, W.; Sun, X.; Cupples, A.M. Identification of Desulfosporosinus as toluene-assimilating microorganisms from a methanogenic consortium. Int. Biodeterior. Biodegradation 2014, 88, 13-19. [CrossRef]

24. Hermon, L.; Denonfoux, J.; Hellal, J.; Joulian, C.; Ferreira, S.; Vuilleumier, S.; Imfeld, G. Dichloromethane biodegradation in multi-contaminated groundwater: Insights from biomolecular and compound-specific isotope analyses. Water Res. 2018, 142, 217-226. [CrossRef] [PubMed]

25. Chaillan, F. Identification and biodegradation potential of tropical aerobic hydrocarbon-degrading microorganisms. Res. Microbiol. 2004, 155, 587-595. [CrossRef]

26. Haddadi, A.; Shavandi, M. Biodegradation of phenol in hypersaline conditions by Halomonas sp. strain PH2-2 isolated from saline soil. Int. Biodeterior. Biodegradation 2013, 85, 29-34. [CrossRef]

27. Tena-Garitaonaindia, M.; Llamas, I.; Toral, L.; Sampedro, I. Chemotaxis of halophilic bacterium Halomonas anticariensis FP35 towards the environmental pollutants phenol and naphthalene. Sci. Total Environ. 2019, 669, 631-636. [CrossRef]

28. Kaczorek, E.; Urbanowicz, M.; Olszanowski, A. The influence of surfactants on cell surface properties of Aeromonas hydrophila during diesel oil biodegradation. Colloid Surf. B 2010, 81, 363-368. [CrossRef]

29. Kumar, M.; Jaiswal, S.; Sodhi, K.K.; Shree, P.; Singh, D.K.; Agrawal, P.K.; Shukla, P. Antibiotics bioremediation: Perspectives on its ecotoxicity and resistance. Environ. Int. 2019, 124, 448-461. [CrossRef]

30. Field, J.A.; Sierra-Alvarez, R. Microbial degradation of chlorinated benzenes. Biodegradation 2008, 19, 463-480. [CrossRef]

31. Peng, Y.H.; Shih, Y.H. Microbial degradation of some halogenated compounds: Biochemical and molecular features. In Biodegradation of Hazardous and Special Products; Chamy, R., Ed.; InTechOpen: Valparaiso, Chile, 2013; pp. 51-69.

32. Bera, S.; Roy, S.A.; Mohanty, K. Biodegradation of phenol by a native mixed bacterial culture isolated from crude oil contaminated site. Int. Biodeterior. Biodegrad. 2017, 121, 107-113. [CrossRef]

33. Szőköl, J.; Rucká, L.; Šimčíková, M.; Halada, P.; Nešvera, J.; Pátek, M. Induction and carbon catabolite repression of phenol degradation genes in Rhodococcus erythropolis and Rhodococcus jostii. Appl. Microbiol. Biotechnol. 2014, 98, 8267-8279. [CrossRef] [PubMed]

34. Basha, K.; Rajendran, A.; Thangavelu, V. Recent advances in the biodegradation of phenol: A review. Asian J. Exp. Biol. Sci. 2010, 1, 219-234.

35. Ren, Y.; Peng, L.; Zhao, G.; Wei, C. Degradation of m-cresol via the ortho cleavage pathway by Citrobacter farmeri SC01. Biochem. Eng. J. 2014, 88, 108-114. [CrossRef]

36. Hage, A.; Schoemaker, H.E.; Wever, R.; Zennaro, E.; Heipieper, H.J. Determination of the toxicity of several aromatic carbonylic compounds and their reduced derivatives on Phanerochaete chrysosporium using a Pseudomonas putida test system. Biotechnol. Bioeng. 2001, 73, 69-73. [CrossRef]

37. Yang, Z.H.; Zeng, R.; Chang, X.; Li, X.K.; Wang, G.H. Toxicity of aromatic ketone to yeast cell and improvement of the asymmetric reduction of aromatic ketone catalyzed by yeast cell with the introduction of resin adsorption. Food Technol. Biotechnol. 2008, 46, 322-327.

38. Muhr, E.; Leicht, O.; González-Sierra, S.; Thanbichler, M.; Heider, J.A. Fluorescent Bioreporter for Acetophenone and 1-Phenylethanol derived from a Specifically Induced Catabolic Operon. Front. Microbiol. 2016, 28, 1561. [CrossRef]

39. Havel, J.; Reineke, W. Microbial degradation of chlorinated acetophenones. Appl. Environ. Microbiol. 1993, 59, $2706-2712$. [CrossRef] [PubMed] 
40. Kamerbeek, N.M.; Olsthoorn, A.J.J.; Fraaije, M.W.; Janssen, D.B. Substrate specificity and enantioselectivity of 4- hydroxyacetophenone monooxygenase. Appl. Environ. Microbiol. 2003, 69, 419-426. [CrossRef]

41. Janicki, T.; Krupiński, M.; Długoński, J. Degradation and toxicity reduction of the endocrine disruptors nonylphenol, 4-tertoctylphenol and 4-cumylphenol by the non-ligninolytic fungus Umbelopsis isabellina. Bioresour. Technol. 2016, 200, 223-229. [CrossRef]

42. Wubbolts, M.G.; Hoven, J.; Meigert, B.; Witholt, B. Efficient production of optically active styrene epoxides in two-liquid phase cultures. Enzyme Microb. Technol. 1994, 16, 887-894. [CrossRef]

43. Panke, S.; Meyer, A.; Huber, C.M.; Witholt, B.; Wubbolts, M.G. An alkane-responsive expression system for the production of fine chemicals. Appl. Environ. Microbiol. 1999, 65, 2324-2332. [CrossRef] [PubMed]

44. Jussupova, D.B.; Golovleva, L.A.; Zhubanova, A.A.; Akimbekov, N. Pathways of $\alpha$-methylstyrene Oxidation by P. aeruginosa DS-26. Eurasian Chem. Technol. J. 2013, 15, 337-344. [CrossRef]

45. Chan, S.I.; Yu, S.S. Controlled oxidation of hydrocarbons by the membrane-bound methane monooxygenase: The case for a tricopper cluster. Acc. Chem. Res. 2008, 41, 969-979. [CrossRef]

46. Moreno, R.; Rojo, F. Enzymes for Aerobic Degradation of Alkanes in Bacteria. In Aerobic Utilization of Hydrocarbons, Oils and Lipids. Handbook of Hydrocarbon and Lipid Microbiology; Rojo, F., Ed.; Springer International Publishing: Cham, Switzerland, 2019; pp. 1-25. [CrossRef]

47. Archelas, A.; Furstoss, R. Synthesis of enantiopure epoxides through biocatalytic approaches. Annu. Rev. Microbiol. 1997, 51, 491-525. [CrossRef]

48. Cropley, R.L.; Williams, F.J.; Urquhart, A.J.; Vaughan, O.P.H.; Tikhov, M.S.; Lambert, R.M. Efficient Epoxidation of a Terminal Alkene Containing Allylic Hydrogen Atoms: trans-Methylstyrene on Cu\{111\}. J. Am. Chem. Soc. 2005, 127, 6069-6076. [CrossRef]

49. Garin, D.L.; Gamber, M.; Rowe, B.J. Epoxidation of Alpha-Methylstyrene and its Lewis Acid Rearrangement to 2-Phenylpropanal. J. Chem. Educ. 1996, 73, 555. [CrossRef]

50. León, R.; Vila, M.; Hernánz, D.; Vílchez, C. Production of phytoene by herbicide-treated microalgae Dunaliella bardawil in two-phase systems. Biotechnol. Bioeng. 2005, 92, 695-701. [CrossRef] [PubMed]

51. Ram, S.; Mitra, M.; Shah, F.; Tirkey, S.R.; Mishra, S. Bacteria as an alternate biofactory for carotenoid production: A review of its applications, opportunities and challenges. J. Funct. Foods 2020, 67, 103867. [CrossRef]

52. Fukaya, Y.; Takemura, M.; Koyanagi, T.; Maoka, T.; Shindo, K.; Misawa, N. Structural and functional analysis of the carotenoid biosynthesis genes of a Pseudomonas strain isolated from the excrement of Autumn Darter. Biosci. Biotechnol. Biochem. 2018, 82, 1043-1052. [CrossRef] 